\title{
IN VITRO ANTI-INFLAMMATORY ACTIVITY OF VACCINIUM LESCHENAULTII WIGHT. (VACCINIACEAE) - AN ENDEMIC MEDICINAL PLANT SPECIES IN NILGIRIS, THE WESTERN GHATS, INDIA
}

\author{
Arumugasamy, K*., D. Sudhakaran, N. Kirthika, H. Abdul Kaffoor and R. Nantha Kumar \\ PG and Research Department of Botany, Kongunadu Arts and Science College (Autonomous), Coimbatore. \\ *E.mail: arumugasamy_kasc@yahoo.co.in
}

\begin{abstract}
Berries of Vaccinium species have been a source of food and pharmaceutical ingredients. The ethanol, methanol and chloroform extracts of Vaccinium leschenaultia was investigated for anti-inflammatory activity. All the extracts $(150$ and $300 \mathrm{mg} / \mathrm{kg}$ each) were found to significantly $(\mathrm{P}<0.05)$ inhibit paw edema induced by carrageenan in rats. The results indicated that the methanol extract with the dose of $300 \mathrm{mgkg}^{-1} \mathrm{~b} . \mathrm{w}$. and the chloroform extract with the dose of $300 \mathrm{mgkg}^{-1}$ b.wt. showed maximum anti-inflammatory activity as compared to the reference drug, Indomethacin. $V$. leschenaultia could be used as a potential source of antiinflammatory agent.
\end{abstract}

Keywords: Vaccinium leschenaultii, anti-inflammatory, Indomethacin.

\section{INTRODUCTION}

Traditional literature shows the use of herbal preparatins in the treatment of inflammation and pain. The search for new anti-inflammatory and analgesic drugs from the medicinal plant resources is intensifying since these shows no side effects (Chatterjee and Pal, 1984). Inflammation is considered as a primary physiologic defense mechanism that helps body to protect itself against infection, burn, toxic chemicals, allergens or other noxious stimuli. An uncontrolled and persistent inflammation may act as an etiologic factor for many of these chronic illnesses (Kumar et al., 2004). Although it is a defense mechanism, the complex events and mediators that are involved in the inflammatory reaction can induce, maintain or aggravate many diseases (Sosa et al., 2002). Currently used anti-inflammatory drugs are associated with some severe side effects. Therefore, the development of potent anti-inflammatory drugs with fewer or no side effects from medicinal plants origin is the need of the hour.

Vaccinium is a genus of shrubs or dwarf shrubs in the family Vacciniaceae. Most are edible and some are of commercial importance, including, the cranberry, bilberry, cocoberry and huckle berry. Acetone and methanol extract of $V$. leschenaultii leaf and fruit exhibited higher anti inflammatory and anti analgesic activity (Poornima et al.,2005). Among the different species of Vaccinium (Bilberries) reported in India, $V$. leschenaultii (Indian cranberry) is considered to be one of the most potent for its medicinal properties. This plant has been used in treatment of several disorders such as mouth ulcer, diarrhea and diabetics. Bilberry fruit extracts have been used for the treatment of diarrhea, dysentery, mouth and throat inflammations (Anon, 2002). Based on the medicinal properties of Vacciniaceae members, the present study was undertaken on Vaccinium leschenaultia $\mathrm{Wt}$. an endemic medicinal plant from the Niligiris, the Western Ghats,India.

\section{MATERIALS AND METHODS}

\subsection{Collection and extraction of plant material}

Vaccinium leschenaultii was collected during blooming season (January 2012) from nearby sholas of Ebanadu, the Nilgiri Hills, Western Ghats, Southern India, Tamil Nadu. The plant was identified and authenticated by a plant taxonomist.

In the acute toxicity studies the various solvents extracts did not cause any mortality even at the heights dose of $2000 \mathrm{mg} / \mathrm{kg}$. Thus the selected plant extracts were safe and non toxic.

Based on acute toxicity studies two different doses were selected to assess anti inflammatory activity in rat models.

The unadultered powdered material of the whole plant of Vaccinium leschenaultii was successively extracted with ethanol, methanol and chloroform in a soxhlet apparatus and concentrated to dryness. These extracts were made free of any solvent by distillation. The various solvent extracts were used as an emulsion in 5\% suspension with gum acacia and administered orally at the dose of 150 and $300 \mathrm{mg} \mathrm{kg}^{-1}$. The animals were grouped in cage in an air conditioned room at the temperature of $22 \pm 1^{\circ} \mathrm{C}$ with 12 hour light and dark cycle. The 
animals were maintained with pellet diet and water ad libitum. They were further segregated in to various groups. This experiment was performed according to ethical guidelines for the investigation of experimental pain in conscious animals (659/02/a/CPCSEA). Intra Gastric Catheter tube (IGC) was used for oral drug administration.

\subsection{Anti inflammatory activity}

\subsubsection{Carrageenan-induced paw oedema in albino} rats (Winter and Poster, 1957)

The wister albino rats were divided into 5 groups comprising five animals in each group. In all groups acute inflammation was produced by sub plantar injection of $0.1 \mathrm{ml}$ freshly prepared $1 \%$ suspension of carrageenan in normal saline in the right hind paw of the rats and paw volume was measured plethysommetrically at 0 to 180 mins after carrageenan injection. All the animals were premedicated with Indomethacin $\left(10 \mathrm{mgkg}^{-1} \mathrm{~b} . \mathrm{wt}\right.$.) orally two hour before infection. Mean increase in paw volume was measured and percentage inhibition was calculated for all the extracts. Wister albino rats of $120-180 \mathrm{~g}$ were subjected to acute and sub acute toxicity studies. A dose of $\mathrm{LD}_{50}$ was determined ideal for pharmacological studies. Percentage inhibition of paw volume was calculated by the following formula

$$
\text { Inhibition }(\%)=\frac{V c-V t}{V c} X 100
$$

\section{Where}

Vt- means increase in paw volume in rats treated with test compounds

Vc- means increase in paw volume in control group of rats.

\subsection{Statistical analysis}

The mean paw volume was expressed in terms of mean \pm SEM and evaluated for statistical significance by ANOVA followed by Dunnett's t-test, $\mathrm{P}<0.05$ was considered by statistically significant.

\section{RESULTS}

The anti-inflammatory activity of ethanol, methanol and chloroform extracts of $V$. leschenaultii was evaluated by carrageenan induced rat paw oedema method. The extracts were tested at two different dose levels. Which were found to be statistically significant (Table 1). $150 \mathrm{mg} / \mathrm{kg}$ b.wt. and $300 \mathrm{mg} / \mathrm{kg}$. b.wt. of ethanolic, methanolic and chloroform extracts of $V$. leschenaultii significantly reduced the carageenan induced paw oedema inflammation as compared with that of the standard drug, indomethacin. The dose effect of $300 \mathrm{mgkg}^{-1}$ b.wt. of the ethanolic, methanolic and chloroform extracts of $V$. leschenaultii was more active than 150

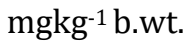

At a dose of $300 \mathrm{mgkg}^{-1}$ b.wt. the methanol and chloroform extract showed a percent inhibition of 86.89 and $61.71 \%$ respectively which are higher than that of reference drug. The ethanol extract at the same dose showed a lower percent inhibition of $39.49 \%$ with respect to reference drug. At $150 \mathrm{mgkg}^{-1}$ b.wt. both the ethanol and chloroform extract shower a lower percent inhibition of 14.68 and $55.98 \%$ in comparison to the reference drug. However, the methanol extract at the same dose showed a higher value of $72.50 \%$. Therefore it in clear that the methanol extract at both the doses of 150 and $300 \mathrm{mgkg}^{-1}$ b.w. showed the maximum percent inhibition as compared to the other extracts of reference drug.

\section{DISCUSSION}

Anti-inflammatory effect of natural products has been frequently assessed through the method of carragenean induced paw oedema. The inflammatory response is a physiological characteristic feature of vascularized tissues (Rang et al, 2007)The inflammatory response is a common feature in many diseases and its control is of relevance in the treatment of these pathologies. There are several herbal drugs used for the antiinflammatory activity. Plants exhibiting antiinflammatory activity reveal that species of 96 genera belonging to 56 families have exhibited such potential (Chawla et al., 1987). Keeping in view the growing significance of anti-inflammatory related herbal medicines in global market, the present antiinflammatory study was been carried out on $V$. leschenaultii (Vacciniaceae) Oedema, which develops after carrageenan inflammation, is a biphasic event. The initial phase is attributed to the release of histamine and serotonin. The oedema maintained between the first and second phase is due to kinin like substances (Vinegar et al., 1969). The second phase is said to be promoted by prostaglandins of lysozymes. The second phase of oedema is sensitive to drugs like hydrocortisone, phenylbutazone and Indomethacin (Winter et al., 1962). The present results of carragennan induced paw oedema model indicated dose dependent anti-inflammatory activity. 
Table 1. Effect of Vaccinium leschenaultii extracts on the percentage inhibition of carrageenan induced paw oedema in rats.

\begin{tabular}{|c|c|c|c|c|c|c|}
\hline \multicolumn{6}{|c|}{ Oedema volume $(\mathrm{ml})$} & \multirow{2}{*}{$\begin{array}{c}\% \\
\text { Inhibition } \\
\text { after } 180 \\
\text { min }\end{array}$} \\
\hline Treatment & $\begin{array}{c}\text { Dose } \\
\mathrm{mg} / \mathrm{kg}\end{array}$ & $0 \mathrm{~min}$ & $60 \mathrm{~min}$ & $120 \mathrm{~min}$ & $180 \mathrm{~min}$ & \\
\hline $\begin{array}{l}\text { Control } \\
\text { (Group-I) }\end{array}$ & $\begin{array}{l}\text { Normal } \\
\text { saline }\end{array}$ & $39.63 \pm 2.16$ & $85.11 \pm 4.15$ & $103 \pm 2.33$ & $123.31 \pm 9.33$ & - \\
\hline $\begin{array}{l}\text { Ethanol } \\
\text { extract }\end{array}$ & $150 \mathrm{mg} / \mathrm{kg}$ & $35.08 \pm 1.57$ & $74.20 \pm 3.60$ & $94.12 \pm 3.18$ & $105.46 \pm 5.43$ & $14.68 \%$ \\
\hline (Group-II) & $300 \mathrm{mg} / \mathrm{kg}$ & $22.11 \pm 2.18^{*}$ & $39.73 \pm 4.05^{*}$ & $63.35 \pm 4.18^{*}$ & $74.77 \pm 3.58^{*}$ & $39.49 \%$ \\
\hline $\begin{array}{l}\text { Methanol } \\
\text { extract }\end{array}$ & $150 \mathrm{mg} / \mathrm{kg}$ & $28.32 \pm 1.95$ & $38.43 \pm 2.18^{*}$ & $31.26 \pm 3.93^{*}$ & $34.24 \pm 2.87^{*}$ & $72.30 \%$ \\
\hline (Group-III) & $300 \mathrm{mg} / \mathrm{kg}$ & $27.02 \pm 1.84 *$ & $21.17 \pm 1.86^{* *}$ & $17.47 \pm 2.69^{* *}$ & $16.21 \pm 1.86^{* *}$ & $86.89 \%$ \\
\hline Chloroform & $150 \mathrm{mg} / \mathrm{kg}$ & $31.37 \pm 1.98^{*}$ & $71.37 \pm 2.67 *$ & $71.16 \pm 2.18^{*}$ & $54.41 \pm 1.69 *$ & $55.98 \%$ \\
\hline frroup-IV) & $300 \mathrm{mg} / \mathrm{kg}$ & $29.31 \pm 1.89$ & $53.43 \pm 2.68^{*}$ & $54.76 \pm 1.98^{*}$ & $47.33 \pm 1.90^{*}$ & $61.71 \%$ \\
\hline (Group-V) & $10 \mathrm{mg} / \mathrm{kg}$ & $25.71 \pm 1.69^{* *}$ & $28.43 \pm 1.94^{*}$ & $49.11 \pm 1.69^{*}$ & $51.75 \pm 2.15^{* *}$ & $58.13 \%$ \\
\hline
\end{tabular}

\section{CONCLUSION}

In the present study Vaccinium leschenaultia methanol extract exhibited maximum and potent anti-inflammatory activity. The importance of this plant as phytotherapeutic for human health especially as an anti-inflammatory agent is proved in this study.

\section{REFERENCES}

Anon, (2002). Vaccinium myrtillus (Bilberry) e Monograph. Alter. Med. Rev. 2001;6:500e4. http://www.altmedrev.com/ publications/6/5/500.pdf.

Chatterjee, G.K., and S.P. Pal, (1984). Search for antiinflammatory agents from Indian medicinal plants- a review. Ind. Drugs 21:413.

Chawla, A., S., Singh, M., Murthy, M.S., Gupta, M. and H. Singh, (1987). Antiinflammatory action of ferulic acid and its esters in carrageenan induced rat paw oedema model. Ind. J. Exp. Biol. 25(3): 187-189.

Kumar, V., A.K. Abbas and N. Fausto, (2004). Robbins and Cotran pathologic basis of disease, 7th edition, Elsevier Saunders, Philadelphia, Pennsylvania, pp: 47-86.
Poornima Nagulsamy, Revathi Ponnusamy and Parimelazhagan Thangaraj, (2015). Evaluation of antioxidant, anti-inflammatory, and antiulcer properties of Vaccinium leschenaultii Wight: A therapeutic supplement. J. Food Drug Anal. 23:376 -386.

Rang, H.P., M.M. Dale and J.M. Ritter, (2007). Local hormones, inflammation and immune reactions. In: Textbook of pharmacology. 6th ed. London: Churchill Livingstone. p. 202.

Sosa, S., M.J. Balicet, R. Arvigo, R.G. Esposito, C. Pizza and G.A. Altinier, (2002). Screening of the topical anti-inflammatory activity of some Central American plants. J. Ethanopharmacol. 8: 211-215.

Vinegar, R., W. Schreiber and R. Hugo, (1969). Biphasic development of carrageen on oedema in rats. J. Pharmacol. Exp. Therap. 166(56): 96103.

Winter, C.A. and C.C.Pster, (1957). Effect of alteration in side chain up on anti-inflammatory and liver glycogen activities in hydrocortisone ester. $J$. Amer. Pharmacol. Soc. 46: 515-519.

Winter, C.A., E.A. Risely and G.W. Nuss, (1962). Carrageenan induced edema in hind paw of the rat as an assay for anti-inflammatory drugs. Proc. Soc. Exp. Biol. Med. 11: 544-547. 